\title{
Zum Text der drei letzten kleinen Propheten.
}

\author{
Von K. Budde.
}

Die drei letzten Bücher der Kleinen Propheten, Haggai, Sacharja und Maleachi - unter Sacharja ist dabei nur das Buch Sach I-8 verstanden - bieten je ein bezeichnendes Beispiel der drei Arten der Überlieferung, die bei Prophetenbüchern vorkommen. Sacharja ist durchgängig Selbstbericht, d. h. der Prophet berichtet mit seinem Ich über die an und durch ihn ergangenen Offenbarungen Gottes; Haggai ist ebenso durchgängig Fremdbericht, d. h. ein Anderer berichtet über seine prophetische Tätigkeit, unter Nennung des Propheten in der dritten Person; Maleachi ist reine Redenfolge, d. h. die Person des Propheten ist völlig ausgeschaltet, das ganze Buch verläuft in Worten Jahwe's, die nur als solche berichtet werden, mit stets sich wiederholenden Anführungsformeln, „spricht Jahwe", "spricht Jahwe der Heerscharen" $\mathrm{x}$ usw. $\mathrm{Zu}$ wenig hat man bisher auf die Berichtform des Buches Sacharja und ihre Erhaltung geachtet. Auf ihre Herstellung in der ursprünglichen Reinheit allein sollen sich die Bemerkungen beziehen, die ich $\mathrm{zu}$ diesem Buche zu biețen habe, während ich bei Haggai und Maleachi eine gründliche Nachlese halten will, die im wesentlichen den Ertrag meiner Seminarübungen im vergangenen Sommersemester darstellt.

I. Zum Buche Sacharja. Daß die Berichtform des Buches Sacharja nicht unverletzt erhalten geblieben ist, hat man schon an

I Die drei Merkworte für die Überlieferungsart sind keine Musterbildungen. Ich wulte keine besseren zu finden; hätte ich a utograph, heterograph, anonym gebraucht, wie ich anfangs wollte, so war allerlei Mißverständnis Tür und Tor geöffnet.

Zeitschrift E. d. alttest. Wiss. Jahrg. 26. 1. 1906. 
einigen Stellen festgestellt, ohne der Frage als solcher nachzugehen. Allgemein einverstanden (Wellhausen, Oort, Nowack, Marti) ist man über 7,8, dessen ויהי דבר יהוה אל וכריה לאמר die Einführung der Worte der früheren Propheten in v. 7 - lies mit LXX אלה רנר ת - von ihrem Wortlaut trennt. Man wird aber nicht mit Marti und Nowack v. 8 und $9^{2}$, sondern mit Wellhausen und Oort nur v. $8 \mathrm{zu}$ streichen haben. Das כה אמר יהוה צבאות לאמר von $9^{a}$ ist die stehende Einleitung des Gotteswortes, zu diesem selbst gehörig, wie 3, 6 im Munde des Engels Jahwes, wie für Sacharja 6, 12. 8, 19 und schon I, 3, so hier für die älteren Propheten. Dalb der Prophet auch deren Rede so einzuleiten plegt, wird durch I, 4 bewiesen. Zum Überfluß kehrt dieselbe Einleitung im weiteren Verlauf dieser Rede in des Propheten Munde immer wieder $(8,2.3 .4 .6 .7 .9 .14$, und in dem neuen Absatz v. I8ff. in v. 19. 20. 23). - Einen zweiten Schritt tun nur Nowack und Marti. Sie streichen in 7, I die Worte und gewinnen dadurch mit einem Schlage ein gesundes Verständnis des höchst unklaren Zusammenhangs. Die ersten Verse ordnen sich nun als Einleitung dem im Selbstbericht redenden ויהי דבר ידוה צבאות אלי לאמר von v. 4 unter. Auffallenderweise ist eine dritte Stelle in diesem Zusammenhang auch von ihnen unbeachtet geblieben. Die Einführungsformel 8, I ist mit ihrem ויהי דבר יהוה צבאות לאמר weder Fisch noch Fleisch, entspricht weder dem Selbstbericht noch dem Fremdbericht: Will man sie halten, wie man es allgemein tut, so muß man vor לאמה ergänzen; aber die schwebende Fassung ist nur ein weiterer Beweis für die Unechtheit des Verses, der hier durchaus nicht an der Stelle ist. Das folgende כה אמר יהוה צבאות hebt den Übergang des Propheten zur Gegenwart vollkommen ausreichend hervor.

Von K. 2-8 ist durch diese Ausschaltungen die Form des Selbstberichts ausnahmslos hergestellt. Es ist von besonderem Werte, daß dies in den beiden entscheidenden Fällen zu 7,8 und 7, I aus rein sachlichen Gründen geschehen ist. Wenn aber Nowack und Marti daneben hervorheben, daß an beiden Stellen gegen die Gewohnheit statt stehe, so muß man sich wundern, daß sie an dem gleichen Vorkommen in Kap. I gar keinen Anstoß ge- 
nommen haben. Und doch begleiten dort kaum geringere sachliche Bedenken die Einführung des Propheten in der dritten Person, als in Kap. $7 .^{x}$ In v. $7 \mathrm{f}$. heißt es: „Am 24. Tage des elften Monats, d. i. der Monat Sebaț, im zweiten Jahre des Darius, gelangte das Wort Jahwes an Sacharja den Sohn Berechjahus des Sohnes 'Iddos, den Propheten, also: Ich sah bei der Nacht, und siehe ein Mann usw. Und das soll der Wortlaut (לאמר!) eines an Sacharja gelangten Gottesworts sein? Was auf לאמר folgt ist überhaupt kein Gotteswort, sondern des Propheten Schilderung von einem Gesicht, das Gott ihn schauen ließ. Zwischen der Zeitangabe in $7^{\mathrm{a}}$ und dem 'ראית in v. 8 darf nicht ein einziges Wort

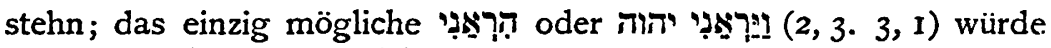
ein ראיתי הלילה erfordern. Die FremdberichtFormel $7^{a}$ ist also einfach zu streichen. Der Fall liegt genau wie in 7, I, wo das Prädikat וישלח ebenso wie das ריתי hon seiner Zeitbestimmung getrennt ist. $\mathrm{Zu}$ dem hergestellten Wortlaute vergleiche man Jes 6, r, zu dem נפתחו das inראה in in in in Hes I, I, wo die Dinge ebenso liegen.

So ausgerüstet treten wir an die letzte Stelle heran, wo die Überarbeitung am tiefsten eingegriffen hat und dem entsprechend auch die Verderbnis am schwersten $z u$ heilen ist. Das ist, wie. gewöhnlich - ich habe Gelegenheit gehabt, es an den Büchern Amos, Hesekiel, Jeremia nachzuweisen ${ }^{2}$ - der Eingang des ganzen Buches. Es ist nicht leicht zu verstehn, daß man sich bei dessen Wortlaut bisher stets beruhigt lfat. Ich setze ihn in Wellhausen's Übersetzung her. "Im achten Monat, im zweiten Jahr des Darius, erging dás Wort Jahwes an den Propheten Zacharia

I Ein Bewußtsein von der Schwierigkeit finde ich nur in W. Rothstein's Schrift Die Genealogie des Königs Jojachin und seiner Nachkommen usw. 1902, S. 38. 44. Er bestreitet die Ursprünglichkeit des Wortlauts, ohne Vorschläge zu seiner Herstellung zu bieten.

2 Vgl. Die Überschrift des Buches Amos und des Propheten Heimat (Semitic Studies, Berlin 1897, S. 106-110); The opening verses of the book of Ezekiel (The Expos. Times, Oct. 1900, Aug. 1901); Die Überschrift des Buches Jeremia (XIII. Orientalisten-Kongreb in Hamburg, 1902, vgl. auch B. Stade in dieser Zeitschrift XXIII, 1903, S. 153 ff.). 
ben Iddo also: Jahwe hat auf eure Väter einen schweren Zorn gehabt. Doch sollst du zu ihnen sagen: so spricht Jahwe Sebaoth! Kehrt um zu mir, sagt Jahwe Sebaoth, so kehre ich um zu euch, spricht Jahwe Sebaoth." Nur $e$ in Bedenken ist dagegen bisher laut geworden: mit Recht hat man längst auf Grund von 1, 7. 7, I angenommen, daß die Angabe des Tages hier verloren gegangen sei. Ein nicht unwichtiger Anhalt dafür, da der Eingang in der Tat gelitten hat; man wird umso schärfer auf andere Spuren zu achten haben. V. 2 eröffnet hinter dem לאמר die direkte Rede Jahwes an den Propheten. Woher dann aber die dritte Person יהוה מצח In der Tat ist dies gerade in der Anrede an den Propheten unbedingt nötig, umsomehr, da die erste Person für Jahwe von dem אל in v. 3 an sogar in der Rede an das Volk ausnahmslos gebraucht wird. Nur wo die Väter redend eingeführt werden, in $6^{b}$, läßt Jahwe sie natülich von sich in der dritten Person sprechen, und ebenso den Propheten, wo er mit כה אמר יהוה צבאות oder נאם יהוה צבאזת Jahwe als den Redenden bezeugen soll. Aber weiter! "Eure Väter", so soll Jahwe zu dem Propheten sagen? In v. 4. 5. 6 kehrt das "eure Väter" wieder, aber jedesmal in der Anrede an das Volk, wofür es sich denn auch allein eignet. V. 2 richtet sich also garnicht an den Propheten, sondern an das Volk, und steht daher an der falschen Stelle. Was soll auch dem Propheten ein Unterricht über die Bestrafung der Väter oder eine Erinnerung daran? Daß der Schluß zutrifft, beweist v. 3. „Doch sollst du zu ihnen sagen" - ich kann nicht glauben, daß Wellhausen ganz ohne Unbehagen sich mit der Anknüpfung des schlichten perf. consec. והמרת zufrieden gegeben hat. Sie ist in der Tat völlig ungenügend. Schlimmer aber ist das אלהם, da es gar kein anderes Beziehungswort dafür gibt als אבותיכם, eure Väter. Wenn Nowack sagt „Das Suffix in אלהם bezieht sich natürlich auf des Propheten Zeitgenossen“, so will das „natürlich “ den Unsinn des Verständnisses kennzeichnen, als wenn der Prophet „eure Väter" anreden sollte; aber der Unsinn fällt vielmehr dem Ausdruck zur.Last. V. 2 gehört eben nicht hierher, 
sondern hinter $3^{a \alpha}$, vor שוּ. Mit dem Hinweis auf die Verwerfung der Väter wird die Aufforderung zur Umkehr an das gegenwärtige Geschlecht und die Verheißung, daß Jahwe zu ihm (עליכם Gegensatz zu (אבותיכם) zurückkehren werde, eingeleitet. Für die Einpügung an der ursprünglichen Stelle ist zunächst קצר יהוה herzustellen; in dem Nachtrag am Rande, von wo aus der Satz nachher falsch eingerückt wurde, hat man der Deutlichkeit halber das Explicitum der dritten Person eingesetzt. Ferner wird

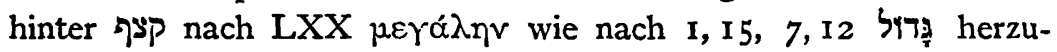
stellen sein. Ob dahinter noch ein „,ihr aber kehret um zu mir“ - mag man fragen; nötig ist es nicht. V. 3 entbehrt nun vollends für ואמרת אלהם jeder Anknüpfung.

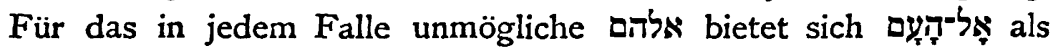
äußerst leichte Herstellung, für die man sich der Form nach allenfalls auf אל כל עם הארץ in 7,5 berufen kann. Vor ואמרת wüde

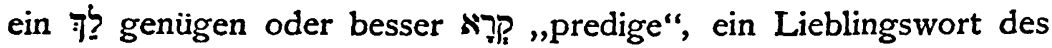
Propheten (vgl. I, 14. I7, auch 1, 4. 7,7). Aber da einmal vor ואטרת sicher eine Lücke besteht, in die jetzt v. 2 irrig eingefügt ist, so kann אלהם auch recht wohl richtig und das Beziehungswort dafür zugleich mit dem ersten Imperativ der Rede Jahwes an den Propheten verloren sein. Ich muß dies sogar für das Wahrscheinlichere halten, zumal es sich um die erste Gottesbotschaft an den Propheten, im Grunde um seine Berufung, handelt. Der Versuch einer Wiedergewinnung des Wortlauts muß für diesen Fall ganz unterbleiben; doch dürfte immerhin nicht viel verloren sein.

So bleibt endlich v. I, der die Stelle der Überschrift vertritt. $\mathrm{Dab}$ er durch Verlust der Angabe des Tages gelitten hat, ist schon festgestellt. Wir aber können uns auch mit der Form des Fremdberichts, der Einführung des Propheten in der dritten Person, nicht zufrieden geben. Haben wir doch bei den beiden übrigen Zeitangaben des Buchs, in 1,7 und 7, I, dasselbe היה דבר יהוה אל 'וכריה ונון als' sinnstörenden Einschub erkannt und beseitigt. Das Buch ist in der Tat in seinem ganzen Umfang Selbstbericht gewesen; mit der ersten Gottesbotschaft, der ersten Zeitangabe muld das Ich des Propheten eintreten. Danach ist $I^{b}$ einfach herzustellen: היה 
דבר יהוה צֵֵלי לאמר. Der Name des Propheten geht damit für den Wortlaut des Buches ganz verloren; aber es wird damit dennoch nicht namenlos. Vielmehr wird aus dem Einschub in $I, I$ und $I, 7$ die Buchüberschrift zurückzugewinnen sein, deren ein als Selbstbericht gefaßtes Buch, sobald es der Öffentlichkeit übergeben wird, nicht entraten kann. Ganz von selbst ergibt sich dafür דבר יהוה

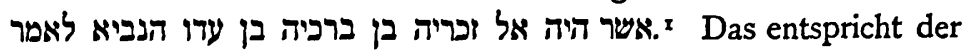
ältesten und häufigsten Form der Prophetenüberschrift, erhalten bei Hosea, Joel, Micha, Șephanja, herzustellen bei Jeremia und Hesekiel. Bei diesem letzten Buche; das in seinem reinen Selbstbericht wie nach seiner geistigen Eigenart dem Sacharjas näher steht als jedes andere, liegt der Fall genau so wie hier. Mit geringer Änderung der Anfangsworte ist auch da die Überschrift als v. 3 in den Anfang des Buchwortlauts eingedrungen.

Dieses genaue Seitenstück, zu dem sich noch das sehr ähnliche des Buches Jeremia gesellt, mahnt zur Vorsicht bei der Erklärung der Erscheinung. Man möchte versucht sein dafür die Annahme Klostermann's (Geschichte des Volkes Israel S. 2 I2f.) heranzuziehen, $\mathrm{da} ß$ Haggai und Sacharja aus einer genau chronologisch geordneten Erzählung über den Tempelbau in den Zeiten des Darius herausgeschnitten seien. Jedenfalls wird durch unsere Ergebnisse Klostermann's weitere Vermutung hinfällig, daß Sacharja selber diese Erzählung zusammengestellt habe. Denn wenn etwas an seinem Buche jener Annahme zugute käme, so wäre es die Überarbeitung in der Richtung des Fremdberichts, die wir nachgewiesen haben; die aber stammt sicher nicht von seiner Hand. Aber vollends wird man doch für Hesekiel nicht ähnliches vermuten wollen. Man darf sich vielmehr im ganzen dabei beruhigen, daß die Überführung prophetischer Selbstberichte in die Form des Fremdberichts ein fast gesetzmäßig fortschreitender Prozeß ist, so oft Redaktorenhand an die Bücher rührt. Ein völlig sicheres Beispiel steht uns, wie ich schon vor zwanzig Jahren nachweisen konnte ${ }^{2}$, an Jes 7 zur

I Die Frage nach der Ursprünglichkeit des ברכיה kommt hier nicht in Betracht.

2 Über das siebente Kapitel des Buches Jesaja, Etudes dédiées à Mr. le Dr. Leemans, Leide 1885. 
Verfügung. Das Gleiche gilt, was noch nicht beobachtet ist, von Hosea I, wo auf Grund von Kap. 3 das Ich des Propheten unbedingt hergestellt werden muß. ${ }^{x}$ Unbegreiflich muß man es nennen, daß umgekehrt Marti Kap. 3 dem Propheten Hosea absprechen will. Man darf ruhig annehmen, daß viele Ich eines Propheten von Redaktorenhand in sein Er umgesetzt sind, kein einziges $\mathrm{Er}$ in sein Ich. Neuschöpfung von Stücken im Selbstbericht aber ist erst ein Kennzeichen des Zeitalters der Apokalyptik.

II. Zum Buche Haggai. Das Buch Haggai ist, wie schon zu Anfang hervorgehoben wurde, von Anfang bis zu Ende Fremdbericht, ist es auch wohl stets gewesen. Wir müssen eben annehmen, daß Haggai seinen Baruch gefunden hat, der seine Gottessprüche treu niederschrieb und der Nachwelt überlieferte ${ }^{2}$; denn den Eindruck großer Treue machen die vier datierten Reden in ihrer frischen Lebendigkeit und Eigenart unbedingt. Das schließt aber nicht aus, daß der Wortlaut in sehr schlechter Erhaltung auf uns gekommen ist; wie mich dünkt, in noch weit schlechterer, als man bisher anzunehmen geneigt ist. Ist das Buch wirklich einmal in einen geschichtlichen Zusammenhang eingefügt gewesen und nachher erst wieder herausgelöst, wie für Haggai außer Klostermann auch Rothstein und Nowack dazu neigen, so mag man dieser Seelenwanderung einen Teil der Schuld an der schlechten Erhaltung beimessen. Inwieweit $z u$ dieser Annahme besonderer Grund vorliegt, werden die nachfolgenden Erörterungen von selbst etwas näher beleuchten.

Haben wir uns bei Sacharja nur mit den Einführungsformeln beschäftigt, so geben die auch bei Haggai allerlei zu raten auf; aber, wie mir scheint, hat man die Lösung neuerdings nach der falschen Seite hin gesucht. Zu dem ביד הגי von I, I bemerkt Marti: ,durch die Hand d. h. vermittelst des Propheten ergeht Gottes Wort nach der späteren Auffassung, die in den Propheten

I Es handelt sich um I, 2.3.4.6.

2 Rothstein, a. a. O. S. 47, bringt das mit der häufig vertretenen Annahme in Verbindung, daß Haggai selbst zu den Hochbetagten von Hagg 2,3 gehört habe. Möglich, aber nicht nōtig. 
gleichsam den Kanal, den Mittler, für die göttliche Offenbarung sieht, s. zu Jes 20, 2 und vgl. Hos I, 2." Nun sind das wohl kaum geeignete Belegstellen für eine „spätere Auffassung"; dazu aber ist Jes 20, 2 offenkundig verdorben und Hos 1, 2 erklärt Marti selbst ganz anders. In der Tat hat man gerade bei der schlicht berichtenden Fassung des Buches durch die zweite Hand an keinerlei Feinheiten oder Eigenheiten des Ausdrucks zu denken, noch weniger sie durch Textänderung erst einzuführen. Alle vier Absätze des kleinen Buches werden durch היה דבר יהוה mit genauer Zeitangabe eingeleitet (vgl. I, I, 2, I. 10. 20). Dazu gehört von selbst ein des Empfängers. Bei der Form des Selbstberichts ist das jedesmal der Prophet, also 'ș, wie überall im Buche Sacharja. Beim Fremdbericht dagegen, wo es sich im Grunde stets nicht um den Empfang sondern um die Ausrichtung der Botschaft handelt, kann an die Stelle des Empfängers der Offenbarung auch der der Botschaft, der von dem Gotteswort Betroffene treten, und der Prophet tritt in diesem Falle von selbst in die Rolle des Mittlers zurück, nicht nach späterer Auffassung, sondern genau dem Sachverhalt entsprechend. Für ihn gesellt sich dann zu dem anderweit vergebenen אל אל des Empfängers das ביד dermittlers. Diese Ausdrucksweise bedeutet eine Abkürzung oder Zusammenziehung. Der Offenbarungsempfang wird $\mathrm{zu}$ Gunsten der Ausrichtung übersprungen, von dem Gotteswort selbst die Anweisung „sprich zu N. N." oder ähnlich erspart. Diese ist also mit dem אל" איד unvereinbar; es sei denn, daß man sich zu dem unerträglichen Wortschwall „So sprach Jahwe zu mir: Sprich zu N. N.: So spricht Jahwe" entschließen wollte. Wo dagegen mit einem bloßen der Offenbarungsempfang bezeichnet wird, da ist diese Anweisung nötig. Für beides haben wir bei Haggai je ein klares und rein-

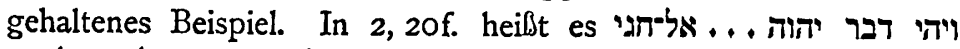

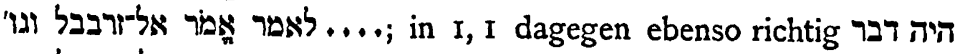
יהוה ביד חגי הנביא אל־זרבבל וגו', worauf dann in v. 2 der Wortlaut

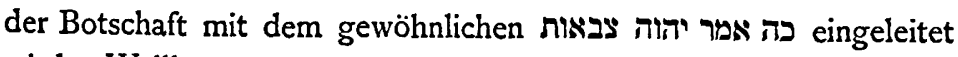
wird. Wellhausen (unter Berufung auf Smend), Nowack, Marti meinen den Text zu verbessern, indem sie hinter הנגביא nach LXX 
$\lambda \varepsilon ́ \gamma \omega v$ Eiròv ein hervor, daß das falsch ist. Das Mehr der LXX beruht auf einem Nachtrag aus 2, If.; zum Überfluß bringen die codd. A und $Q$ mit ihrem $\delta$ ǹ auch das vergessene $\$$. Aber es ist weiter zu gehn. Der jetzige Wortlaut von 2, If. „Das Wort Jahwes erging durch den Propheten Haggai: Sprich doch zu Serubbabel usw." gibt keinen Sinn. Das "Sprich doch zu Serubbabel“ ist nicht durch Haggai sondern an Haggai ergangen und wird in der durch bezeichneten Weitergabe eben durch seine Befolgung überflüssig. Eine von zwei Änderungen muß vollzogen werden. Entweder לאמר אמר-נא ist zu streichen, sodaß die Einführung I, I entspricht,

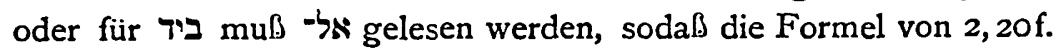
entsteht. Das letztere ist einfacher und wird das Richtige sein. Dann ist zuerst 2, I gedankenlos, ohne auf die Verschiedenheit des Falles zu achten, I, I angepaßt worden; die LXX oder ihre Vorlage hat dann vollends auch $\mathrm{I}, \mathrm{I}$ nach 2 , I f. verändert und so die beliebte Uniformität durch Addition herbeigeführt. Lies also in

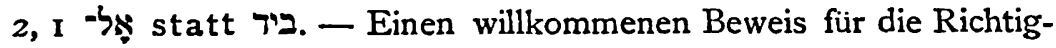
keit liefert 2, 13, wo wir um einen Schritt hinter den Tatbestand von 2, I f. zurückgeführt werden. Da lautet die Vulgärlesart, unterstützt von Targum und Syrus, ביד, die besten Handschriften aber, fast alle alten Ausgaben, LXX, Itala, Vulgata, Arabs, bieten - אל ית, und mit Recht haben Baer und Ginsburg das in den Text aufgenommen. Hier ist also der Versuch der Uniformisierung auch gemacht, aber nicht durchgedrungen. Nur die letzte Stelle endlich, 2,20f., blieb, wie das so die Regel ist, ganz unbehelligt. Damit ist aber die Sache keineswegs erledigt. Während Wellhausen, Nowack, André in 2, 10 - $\$$ annehmen, besteht Marti auf der Richtigkeit des ביד, weil bei "IIa noch weniger zu erwarten wäre, als im gegenwärtigen Texte." Das ist richtig: mit „So spricht Jahwe der Heerscharen" kann keine persönliche Mitteilung Jahwe's an den Propheten beginnen, sondern nur die vom Propheten an Andere ausgerichtete oder auszurichtende Botschaft. Aber Marti selbst deutet an, dab auch ביד nur einen Notbehelf liefert. Es fehlt dafür die Angabe der Betroffenen, und da der 
Auftrag שאל-נא sich an den Propheten selbst richtet, auch dafür der klare Ausdruck. Es mübte also etwa heißen ביד תגי הגביא

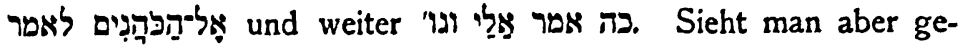
nauer zu, so muß man erkennen, daß I Ia mit seinem 'כד אמר יהוה צ' überhaupt nicht hierherpaft. Es widerspricht der Absicht der Vexierfragen, die Haggai an die Priester richtet, daß der göttliche Befehl dazu mit ausgerichtet wird. Sie werden als Sachverständige befragt, und Haggai mu囚 dabei zunächst als des Bescheides wirklich bedürftig erscheinen. Der Urtext ist also dadurch herzustellen, $\mathrm{da} ß$ man die Lesart ${ }^{2}$ aufnimmt, I I ${ }^{\mathrm{a}}$ aber einfach streicht. Das „So spricht Jahwe der Heerscharen" ist ganz gedankenlos als die gewöhnliche Einleitung des Gottesworts hinter dem לאמר ergänzt. Daß hinter $12^{2}$ die Ausführung des Befehls zwischen den Zeilen zu lesen ist, versteht sich von selbst; richtiger wird man sagen müssen, daß auch die göttliche Anweisung zu der zweiten Frage und den auf die Antwort folgenden Schlüssen zwischen den. Zeilen gelesen werden muß. $Z \mathrm{u}$ vergleichen ist damit Jes $7, \mathrm{I}-1 \mathrm{I} 3$. - Noch eine fünfte Einführung eines Gottesworts findet sich, aber ohne Zeitangabe, auch durch die unvollständige Form den ungeschickten Einschub verratend, nämlich $\mathrm{I}, 3$, „Und ẹs erging das Wort Jahwes durch den Propheten Haggai also". Marti meint es erklären zu müssen, daß trotz der direkten Rede des Propheten nicht dasteht; Hitzig sagt: „Die ungeschickte Wendung des zweiten Verses, wo Jahwe ihnen sagt, was bisher das Volk gesprochen habe, macht die Wiederaufnahme seiner ersten Hälfte durch v. 3 notwendig, welcher nämlich nicht als von Jahwe gesprochen (= und so geschieht mein Wort usw.) anzusehen ist". Nichts ist hier ungeschickt als der Vers selber. Er ist eingeschoben von jemand, der das Gotteswort ausdrücklich von dem Worte des Volkes in $2 b \beta$ meinte unterscheiden $z u$ müssen und den Wortlaut dafür flüchtig aus v. I entlehnte. Sobald man ihn streicht, ist alles in schönster Ordnung.

Und nun mag die Behandlung der Textfolge nach weiterschreiten.

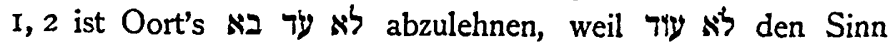
"noch nicht" nicht hat. 


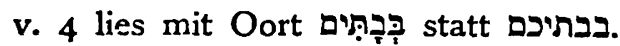

v. 6 könnte

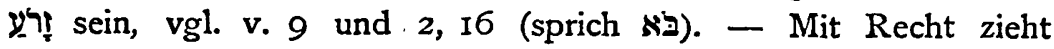

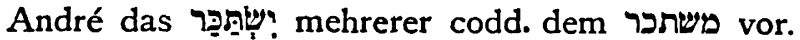

v. $7^{\mathrm{b}}$ pflegt man seit Wellhausen zu streichen. Daran ist richtig, daß die Wendung שימו לבבכם על דרכיכם, nachdem sie in $5^{b}$ auf das Ergehn und die Vergangenheit bezogen war, hier nicht auf einmal das Verhalten und die Zukunft meinen kann, was doch vor v. 8 nötig wäre. Die Auskunft von Köhler, André usw. ist also unzulässig. Aber daß man glaubt mit der Streichung des Verses alle Not beseitigt zu haben, muß Wunder nehmen. Ist es denn denkbar, daß gleich nach der Aufforderung zu dem pflichtmäßigen Handeln in v. 8 die Aufzählung der bisherigen Mißerfolge, die in v. 6 voraufgegangen ist, in v. 9 wieder aufgenommen würde, als wenn sie nie verlassen wäre? Die Unordnung erscheint in der Übersetzung etwas weniger auffällig, weil man die Inff. abss. von v. 9 in das verb. fin. auflöst, „Ihr erwartet" usw., ohne daf. sachlich damit etwas gewonnen wäre. Im Hebräischen ist auch die Form unmöglich, da die Reihe der Inff. abss. einer unmittelbaren Anknüpfung nach rückwärts bedarf, die v. 8 durchaus nicht bietet. Nicht $7^{\text {b }}$ ist $z u$ streichen, sondern v. $8 \mathrm{muß}$ an seine richtige Stelle zurückversetzt werden. Er gehört unbedingt hinter v. 4, unmittelbar hinter den Vergleich zwischen den behaglichen Häusern der Bewohner Jerusalems und der öden Stätte des Hauses Jahwes. Dann erst erhält auch das ועת zu Anfang von v. 5 durch den Gegensatz den rechten Sinn. Hat man v. 8 fortgenommen, so ist v. $7 \mathrm{im}$ vollen Umfang $z u$ halten; die Aufforderung v. 5 wird vor einer zweiten Reihe von Unglücksbildern nachdrücklich wiederholt, genau wie $2,15^{a}$ in $v .18^{a}$ vor der neuen Reihe v. 19.

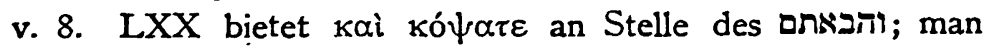
sollte das nicht unerwogen lassen. Denn in der Tat ist doch das Holzhauen die Hauptsache. Leicht würde sich die Verderbnis erklären aus roden" ohne $Y Y$ in sich schlieft, mag der ursprüngliche Text 


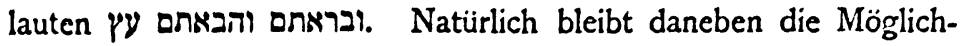

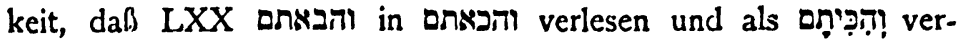
standen hat. Das ואפברה ואפבד heilit schwerlich "und dafo ich dann mich verherrliche", "meine Herrlichkeit offenbare", sondern „meine Ehre empfange", „meine Ehre mir werde". Vgl. noch unten $z$ u v. II.

v. 9. והנה mit LXX $2 \mathrm{~m}$ lesen, wird durch 2,16 dringend empfohlen; am besten folgt man LXX auch in der Streichung des ל vor das in 2,16 ebenfalls fehlt. - Am

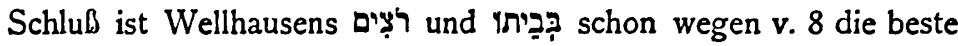
Herstellung.

v. 10. עליכם "über euch“ ist gut, und seine Stelle durch den Nachdruck gerechtfertigt; zudem kann es ebenso leicht von LXX oder der Vorlage hinter על על כוbersehen, wie aus dessen Wieder-

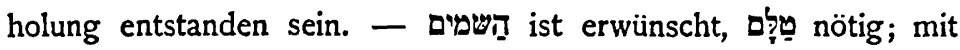
Recht ist dafür auf Sach 8, 12 verwiesen worden.

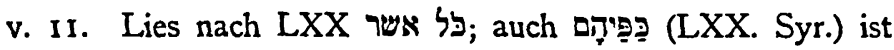
wohl zu erwägen, trotz des dazwischen tretenden ועל־הבהמה Mit v. I I bricht die Rede auffallend plötzlich ab. Man muß unbedingt erwarten, daß Haggai auf die Erklärung der ungünstigen Vergangenheit und Gegenwart noch einmal eine nachdrückliche Mahnung zum Tempelbau und die. Verheißung einer besseren Zukunft hat folgen lassen. $\mathrm{Daß}$ die letztere jetzt völlig fehlt, hat den Hauptanlaß geboten, in dem ואכבד von v. 8 die Verheißung der messianischen Zeit zu finden; aber selbst wenn man den so verstandenen Vers statt hinter v. 4 hinter v. I I einrückte, wäre dem, was man erwarten muß, noch kein.Genüge geschehen. Vielmehr muß man nach v. 4 die Mahnung, nach v. II erneute Mahnung und Verheißung durchaus erwarten. Fragen kann man nur, ob schon der erste Berichterstatter Haggais Rede so zusammengezogen hat, ober ob erst nachher hinter v. II der Abschluß verloren gegangen ist. Das'letztere ist das wahrscheinlichere. Dürfte man in v. I $2 \mathrm{ff}$. eine nachträgliche geschichtliche Einschaltung sehen, so wäre auch die Gelegenheit dafür gefunden. Indessen ist dazu kaum Anla, , da die Verse der Überlieferung des ganzen 
Buches im Fremdbericht durchaus entsprechen. Eher darf man annehmen, daß

v. I3, der neuerdings mit Recht von allen ausgeschieden wird, in dem יאני אתכם נהם יהוה einen Rest oder Auszug des verloren Gegangenen erhalten hat. Zuerst am Rande mit feierlicher Einleitung nachgetragen, wäre diese Reliquie später an falscher Stelle in den Text eingerückt worden. Daß der Satz als $2,4^{\mathrm{b}}$ wiederkehrt, wäre kein Grund dagegen.

v. I5. Weit gehn die Ansichten auseinander, ob der Vers als Zeitangabe für $14^{b} z u$ verstehn sei, sei es in ursprünglichem Zusammenhang (Wellhausen) oder als Nachtrag (Marti); oder vielmehr als Einleitung zu einem, verlorenen Abschnitt, sei dies nun die Weissagung Sach 8,9-I3 (Klostermann) oder ein geschichtliches Stück (Sellin, Rothstein, Nowack). Im Recht ist Wellhausen, aber erst nach Herstellung des ursprünglichen Wortlauts. Den Schlüssel bietet das unmögliche בששי, an dem merkwürdigerweise kein Ausleger Anstoß nimmt. Natürlich wäre der ביום Text ganz in Ordnung, wenn man an den Anfang vor

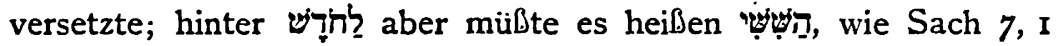
und eine Menge andrer Stellen beweisen, auch wenigstens eine Handschrift bei de Rossi verbessert. Es handelt sich eben um flüchtiges explicitum; alles von בששי an ist müßiger Zusatz, da Monat und Jahr.sich aus I, I von selbst ergänzt. Das falsche 2 aber beruht auf einer Änderung, die an dem ersten Worte vollzogen ist; man hat auch hier uniformisiert, indem man nach I, I. 2, 1. 10. 20 aus (vgl. 2, 18. Esr 3,6) ein gemacht hat. "Und sie kamen herzu und taten Arbeit am Hause Jahwes ihres Gottes vom 24. Tage des Monats an": so lautet der ursprüngliche Schluß von Kap. 1.

Kap. 2. v. 2. Nach LXX und Syr. lies mit Marti כָל שָשארית wie I, I2. 14.

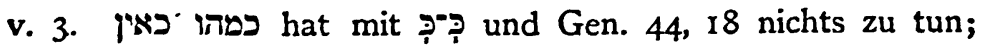
במהi heißt einfach ,seinesgleichen, dergleichen, so etwas“.

v. 5. Die Streichung von a $\alpha$ bis nach LXX, über die fast alle Neueren einig sind, schafft wohl Erleichterung, aber 
keine Erklärung; daß der Wortlaut des Ausgeschiedenen nicht in Ordnung ist, sollte stutzig machen. Auch ist der Schaden nicht beseitigt, wenn man eine Erklärung für das $ת$ am Anfang bietet, wie das am besten Marti getan, indem er den Satz als Glosse hinter a $\beta$ verweist, „mein Geist, samt dem Worte usw." Denn הדבר אשר ist unmöglich; es muß entweder heißen הרבר אשר כרתי

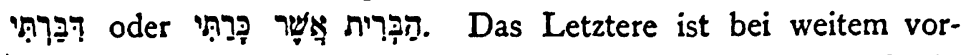
zuziehen. Das את aber wird irrige Wiederholung der letzten Buchstaben von צein; es zog die Änderung des ursprünglichen

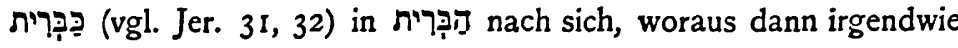
הדבר wurde. Ob man dann noch in 5 a $\alpha$ eine Glosse sehen will, ist teils Geschmacksache, teils eine Frage der Schätzung des Zeugnisses der LXX, in deren besten Handschriften der Absatz fehlt. Jedenfalls hat die Herleitung aus Jes. 59, 2 I (Marti) nichts Überzeugendes.

v. 9. Zu Wellhausens vortrefflicher Rückübersetzung des Mehr der LXX am Schlusse des Verses habe ich nur den Vorschlag is hinzuzufügen. Das 1 könnte in der Umstellung

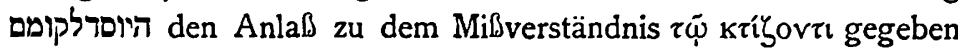
haben. Der so hergestellte Wortlaut ,und Ruhe der Seele zur Wiederherstellung des ganzen Unterbaus und zur Aufrichtung dieses Tempels" könnte recht wohl ursprünglich sein, zumal der hebräische Text sehr kurz abbricht. Daß ihm das ניאם יהוה צבאות vorausgeht, ist alles andre eher als ein Gegengrund (Marti); es schiebt sich auch I, 9. 2, 4a. 4f. 8f. 14. 23 a (zweimal) als $Z$ wischensatz mitten in den Zusammenhang ein.

v. I2. Lies nach LXX וגנע

v. I4. Hier ist der Zusatz der LXX nicht für echt zu halten, vor allem weil Haggai nirgends von Begehungs- sondern nur von Unterlassungssünden redet.

v. I5. Daß die Überlieferung den Sinn falsch auffaßte, beweist die falsche Versabteilung; denn mit מטרם muß ein neuer Vers beginnen. מעלה geht natürlich wie I Sam 16, I3. 30, 25 auf die Zukunft.

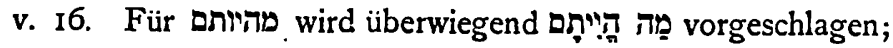


noch besser, weil eigentümlicher hebräisch, ist Martis erster Vor-

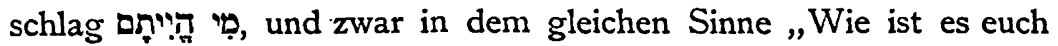
ergangen?" Vgl. dazu Ruth 3, I6. Am 7, 2. 5. - Natürlich ist

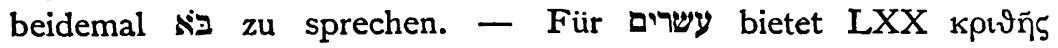

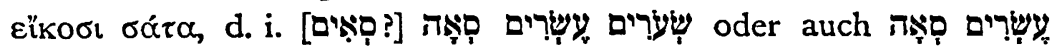
שִׁעy Schwerlich darf das vernachlässigt werden. Leicht konnte aus der Vorlage der LXX, besonders in der zweiten Gestalt, der überlieferte hebräische Text werden, während ein Entstehn des Mehr auf dem Boden der LXX, besonders angesichts des hebrä-

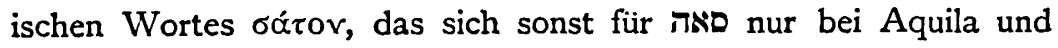
Symmachos findet, ganz ausgeschlossen ist. Dagegen darf man

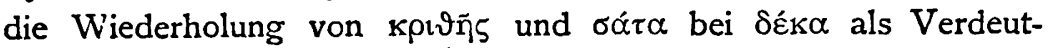
lichung ansehen. - - scheint mir gut, wenn man darunter den kleineren oberen Hohlraum, die eigentliche Kelter versteht, in der die Trauben getreten werden (Jes. 63,3), der daher wiederholt gefüllt wird, um den gekelterten Saft in den größeren unteren Hohlraum, den 2קיף, ausfließen zu lassen. פורה bedeutet dann je eine Füllung der Kelter mit Trauben. Soll פורה dasselbe wie בי ' bezeichnen, so ist es Glosse dazu (Matthes, Marti), was doch angesichts der Seltenheit des Wortes nicht wahrscheinlich heißen darf. Jedenfalls ist

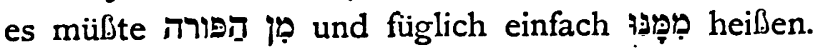

v. I7. Der Vers ist ohne Zweifel mit Wellhausen als Glosse

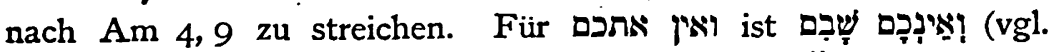
LXX) die beste Herstellung, zumal sich bei der Ähnlichkeit von כ בם und die Verderbnis leicht erklären läßt.

v. I8. Nur die Zeitbestimmung von מיום bis לתשיעי ist sicher Einschub, schon weil sie nach v. Io überflüssig ist und den Wortlaut in unerwünschter Weise belastet; der Schluß des Verses von ib an kann dann echt sein (so Wellhausen Text), wenn man unter „dem Tage, an dem der Grund zum Tempel Jahwes gelegt wurde", den des Beginns der Arbeit am Tempel (I, I 5) verstehn darf. Dann wird der Termin der ersten Vershälfte in der zweiten begründend zurückverlegt, „von heute an, [im Grunde] von dem Tage der Arbeit am Tempel an"; und das ist vollkommen möglich, 
weil auch an jenem Tage über die Ernte des vergangenen Jahres schon entschieden war. Anders versteht Stade (Biblische Theologie d. A. T. I S. 314) den Zusammenhang, wenn er aus unserm Verse entnimmt, daß eben am 24. des 9. Monats der Grundstein gelegt, d. h. natürlich die Feier der Grundsteinlegung gehalten wurde, im Unterschiede von dem Angreifen der Arbeit am 24. des 6. Monats. Indessen sollte das doch in v. 10 ausdrücklich gesagt sein, und die Verhandlung mit den Priestern spricht eher dagegen. Möglich bleibt natürlich auch die Streichung des ganzen zweiten Halbverses (Wellhausen in den Anmerkungen). Wichtig ist jedenfalls die Wiederholung der Aufforderung $15^{a}$ in $18^{a}$, der Unfallsreihe v. 16 in v. 19, weil damit unsre Lösung der Schwierigkeiten von I, 7-9 bestätigt wird.

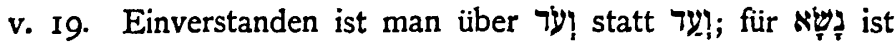
nicht nur נلֵֶ auszusprechen, sondern unter Verdoppelung des

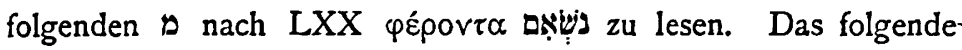
карлóv kann freie Ergänzung sein; immerhin ist zu beachten, daß נשא vom Pflanzenwuchs, ob eigentlich oder bildlich, sonst nie ohne Objekt steht, mit 'רִ Yุ Hes. 17,8. Jo 2, 2. Ohne Zeugen aber wird vor $b$ ein durch Übergang von dem ersten משאמביאמטן sehr leicht ausfallen konnte. Der unvermittelte Einsatz der Verheißung in b ist kaum erträglich. - Eine harte Nuß bleibt das העוד הזרע במגורה. Das kann als Nominalsatz nur auf die Gegenwart bezogen werden: „Ist das Saatkorn noch im Vorratsraum?", diese Bedeutung von מגורה zugegeben. . Die Zusagen von v. I9 scheinen aber doch lediglich auf die Zukunft zu gehn; dafür bedarf

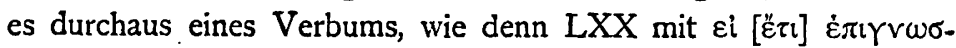

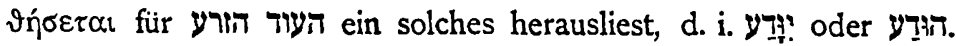
Zudem klingt es doch fast abenteuerlich, daß die Aussaat wegen mangelnden Regens überhaupt nicht aus der Scheuer käme. Ich möchte anheimgeben, ob hinter הזרע etwa ein übersehen ist, im Sinne von keimen, darum, wenn es im Vorratsraum ge-

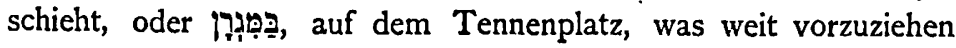
wäre, auswachsen, sodab das Saatkorn zu grunde geht. Das 
bedeutete übermäßige und unzeitige Nässe statt Trockenheit. Freilich liegt das im. Orient keineswegs nahe; aber etwas sonst Unerhörtes dürfte hier wohl angeführt werden. Die andre Möglichkeit ist, daß von der nächsten Vergangenheit geredet würde. Dann dürfte im Dezember gefragt werden, ob etwa [auch dies Jahr] das Saatkorn noch in der Scheuer sei, und ob wiederum, in diesem

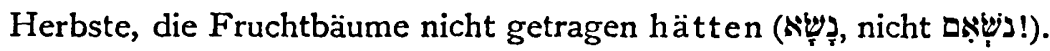
Das letztere würde wesentlich erleichtert durch das Zurückgreifen auf den September in $18 \mathrm{~b} \beta$. Wenig stimmt dazu freilich das Imperfektum אברד.

v. 2 I. Das Mehr der LXX hat keinen Wert.

v. 22. Vielleicht ist für das erste ממלכות nach LXX (freilich

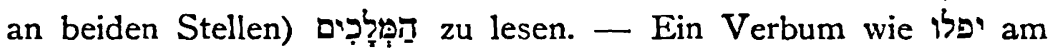
Ende hinzuzusetzen (Wellhausen) scheint mir bei prägnanter Auffassung von וירדו ïberflüssig.

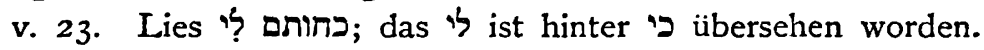
Vgl. Jer. 22, 24 .

Für die beliebte Annahme, daß das Buch Haggai aus dem Zusammenhang einer Erzählung über den Tempelbau herausgelöst sei, dürfte die eingehende Untersuchung seines Textes kaum neue Anhaltspunkte geliefert haben, während ihr durch die Herstellung von I, I5 der scheinbarste Beweis entzogen ist.

III. Zum Buche Maleachi. Das Buch vertritt, wie schon eingangs bemerkt, die dritte Möglichkeit dér Fassung prophetischer Bücher, einfache Redenfolge, ohne jede Berichtform. Nur eine Einführung ist deshalb zu besprechen, die Überschrift

Kap. I. v. I.. Ihre Fassung משא דבר יהוה אל-ישראל fällt - mit der von Sach 9, I. 12, I zusammen; LXX ह̇ंi bietet auch das לy von Sach 12, I. Maleachi wird damit als dritter Anhang zum Buche Sacharja, oder ursprünglicher zu der Sammlung kleinerer prophetischer Schriften, gekennzeichnet. Die ältere Zeit der. Redaktion scheint eben namenlose Bücher nicht ausgeschlossen, sondern am Ende der Sammlung angefügt zu haben; erst später gelangte der Grundsatz zur Geltung, daß namenlose Stücke dem letztbenannten Verfasser zuzurechnen

Zeitschrift f. d. alttest. Wiss. Jahrg. 26. I. 1906. 
seien. Das משט dürte an allen drei Stellen erst nachträglich vorgesetzt sein, ebenso wie משא נינוה dem Buche Nahum, המשא dem Buche Habakuk und die sämtlichen Massa-Úberschriften in Jes 13-23. Es handelt sich um das Modewort einer bestimmten Redaktionsphase. - Für den zweiten Halbvers bietet LXX die ursprünglichere, auf 3, I beruhende Gestalt ביד מלאכו, aus der dann erst ein noch peinlicherer Anschluli an den Buchstaben von 3, I den Eigennamen מִ zu Tage förderte. Wäre das nicht geglückt, so möchte wohl zur Auffullung der Zwölfzahl neben Jona noch ein weiterer Prophetenmidrasch seinen Weg in den Prophetenkanon gefunden haben. Nur an die ältere Form „durch seinen Engel" schließt sich der Zusatz an, den die LXX bietet, ง๕์ $\sigma \varepsilon$

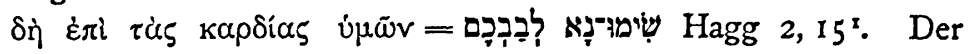
Zusatz will wohl nicht, wie Torrey vermutet, Haggai als Verfasser ansprechen, sondern zu besonders ernster Beherzigung mahnen, weil hier der Engel Jahwes selber rede.

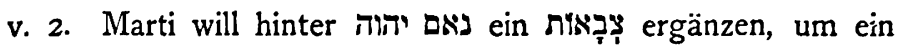
volles Versglied, das letzte seiner ersten Strophe, zu gewinnen. Dagegen ist zunächst zu bemerken, daß in $2 \mathrm{a}$ אמר יהוה auch ohne צבאות steht. Dazu kommt aber, daß sich נאם יהוה im Buche Maleachi nur dies einzige Mal findet; man dürfte also viel eher fragen, ob es nicht ganz zu tilgen ist, zumal so dicht hinter dem אמר יהוה, צus das mit oder ohne צweidutzendmal vorkommt,

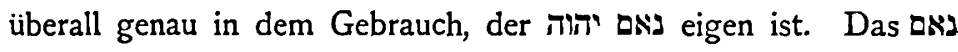
יהוה dürfte eingeschoben sein, um die dem Buche eigene Form der Wechselrede zwischen Jahwe und menschlichen Personen an - dieser ersten Stelle sofort deutlich herauszuheben. - Es muß gleich bemerkt werden, daß dies keineswegs das einzige Mal ist, wo bei Marti metrische Beweggründe, besonders das Strophensuchen, das Urteil über den Text Maleachis in bedauerlicher Weise beeinflussen. Wie schwach es um das gesuchte Vers- und Strophenmaß bestellt ist, kann gleich an unsrem Verse gezeigt werden. Mit ואהב soll die zweite vierzeilige Strophe beginnen! Und während נמ

I Genau diese Übersetzung bieten dort bei Swete $\times c . b$ AQr, wāhrend B ei५ statt $\varepsilon \pi l$ hat. Schon Hieronymus leitet den Zusatz von dort her. 
יהוה zu drei Hebungen ergänzt wird, werden ואהב אתיעקב und ohne jede Bemerkung als Versglieder von ausreichender Länge verrechnet. Die beiden Sätze bilden zusammen eine Zeile von vier Hebungen, so gut $2 \mathrm{a} \alpha$ deren vier hat, ohne daß Marti sich daran stößt. Man gebe doch die Kleinkrämerei mit der metrischen Wage auf, da man damit überall die Erstgeburt für ein Linsengericht verkauft!

v. 3. Den zweiten Halbvers auf die Zukunft zu beziehen, wie kürzlich wieder v. Bulmerincq auf dem Orientalistenkongreß in Algier vorschlug, halte ich für unmöglich. Will man es, so spreche man wenigstens

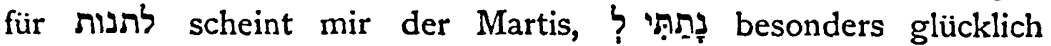
zu sein.

v. 4. Da das Femininum für אדום durch die 1. pl. der folgenden Rede besonders erschwert wird, muß man ernstlich erwägen, ob für ת תicht nמֵר zu lesen ist. Leicht könnte man nach Ia $\beta$. 5b usw. die zweite Person erwartet und irrig geschrieben haben. - עד־עולם zu streichen dürfte Marti (nach Sievers) unbewußt mehr durch das gesuchte Metrum veranlaßt sein als durch den angeführten Grund, daß „die Juden zur Zeit Mal's doch nicht sehen konnten, daß Edom auf-immer gehaßt sei“". Die Juden reden ja erst in $5 \mathrm{~b}$, in $4 \mathrm{~b}$ dagegen die Welt uberhaupt und in allen zukünftigen Geschlechtern. Und wie sollten solcher Gewissenhaftigkeit gegenüber ungezählte Stellen bestehn?

v. 6. Richtig schiebt man seit Smend (bei Wellhausen) nach dem Zeugnis der LXX $^{x}$ ein ארָ: zwischen ועבד und ein hübsches Beispiel für den Ausfall durch Ähnlichkeit der Buchstaben. - Man lese aber ferner durch Wiederholung des folgenden Buchstaben אָָּ statt des ersten אבו

v. 6f. Der Text ist hier schwer zu Schaden gekommen, was freilich auf den ersten Blick nur an v.' 7 klar wird. Mit Recht erklärt Wellhausen es für ungenügend statt ג nach LXX

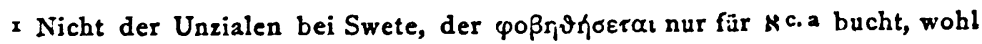
aber der Minuskeln 22. 36. 51.62.68 usw. 


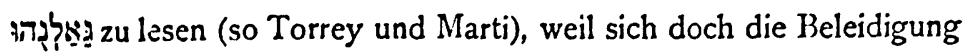
gegen den Altar, nicht gegen das Brot richte. Noch schwerer wiegt, daf die Priester in 7 a $\alpha$ geradezu beschuldigt werden, unwürdige Speise auf dem Altar dargebracht zu haben, und das in $7 \mathrm{~b}$ dahin abgeschwächt wird, dalj sie nur gesagt hätten, der Tisch Jahwes werde verachtet oder sei gering zu achten. Dab dies dann vollends die dargebrachte Jahwespeise selbst soll unwert gemacht oder gar beschmutzt haben, lälit sich gar nicht begreifen. Leider bringt aber auch Wellhausens Vorschlag (von Nowack gebilligt) keine volle Heilung. Er streicht 7 aß ואמרתם במה גאלנוך und übersetzt dann v. 7: "Ihr bringt unwertes Brod auf meinen Altar dar, indem ihr denkt (באמרכם), der Tisch Jahwes sei gering zu achten". Das geht darum nicht an, weil dasselbe באמרכם in v. 12 und 2, 17 nicht die Entschuldigung sondern die Schuld selber bezeichnet. Bei der formelhaften Haltung des ganzen Buches ist darauf entscheidendes Gewicht zu legen. Vielmehr ist zu beachten, daß der von Wellh. ausgeschiedene Satz die beiden ersten Worte mit dem letzten Satze von v. 6 isemein hat. Davon ist das erste nur einmal zu setzen, im übrigen aber $7 a \beta$ samt $b$ mit einem $i$ an v. 6 anzuhängen, worauf dann vor v. 7 mindestens noch ein

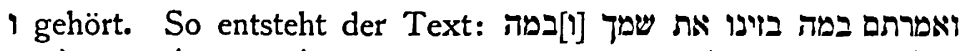

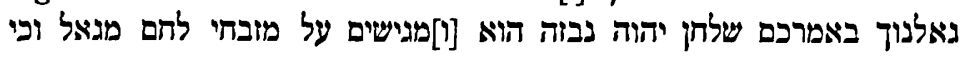
תגשון וגו' Das hat auch den nicht zu unterschätzenden Vorzug, daß dann der erläuternde Satz v. 8, ובי תגשון וגון, unmittelbar auf die Aussage מגישים וגו folgt. Die Umstellung ist vielleicht so $z \mathrm{u}$ erklären, daß zunächst ein Schreiber von dem בעצ מעו את zu zu - Ende von v. 6 auf das נבוה הוא zu Ende von v. 7 hinglitt und deshalb mit $7 a \alpha$ fortfuhr. Der übersehene Absatz wurde am Rande mit der verdeutlichenden Einleitung is nachgetragen und eben um dieser neuen Einleitung willen als neues Glied der Zwiesprache hinter der ersten Antwort wiedereingefügt. Fragen kann man noch, ob vor מגישים zu Anfang von v. 7 statt eines bloßen $I$ ein İָ ausgefallen ist. Dann wäre der Sinn: „Ihr klagt, daß der Tisch Jahwes [von Andern] verachtet werde, und ih $r$ selber bringt auf meinem Altare unwertes Brot dar". Nötig ist 
noch die Einfügung des zweiten Vorwurfs, gegen den die Priester

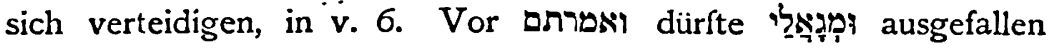
sein, vielleicht mit Bedacht gestrichen, als $7 \mathrm{a} \beta . \mathrm{b}$ verloren gegangen waren.

v. 8. Von hier an streicht Marti bis zu Ende des Kapitels nicht weniger als sechs אמר יהוה צבאות und läbt nur das eine am Schluß von v. I3, nach LXX ergänzt, stehn. Von den 5 in Kap. 2 fällt nur eins, von den Io in Kap. 3 nur 4 oder 5, weil er die übrigen für seinen Vierzeiler ebenso nötig hat, wie jene ihm im Wege stehn. Wenn man sieht, wieviel außerdem noch mitgehn muß, und wie fragwürdig manche "Strophen" dennoch ausfallen, kann man es nur beklagen, daß diese Rücksicht, obwohl nirgends geltend gemacht, doch überall unbewußt die entscheidende ist. - הירנָּה ist mit Wellh. usw. vorzuziehen.

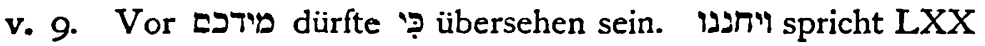

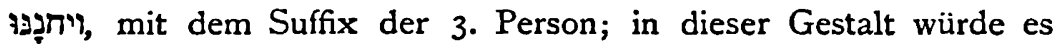
hinter פנים gut am Platze sein.

v. I I. Es scheint mir fraglich, ob פגש zu streichen oder vielmehr

v. 12. An der Stelle von וניבו wäre ing vortrefflich, könnte auch vor נבוה - etwa in der Schreibung ומובחה leicht übersehen sein.

v. 13. Der erste Absatz scheint mir zu eigenartig, um ihn mit Wellhausen für müßige Wiederholung' zu erklären; allerdings dürfte in dem אות ein Schaden stecken, der durch den Vorschlag 'אוֹ (Graetz, Nowack, Marti) nicht ausreichend geheilt wird. Ob man an

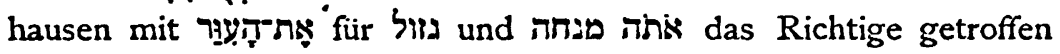
haben. - Am Schluß kann man mit Marti nach LXX צִָּ ergänzen.

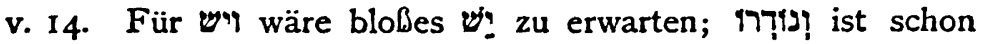
mehrfach nach LXX verbessert. Auffallend bleibt die Gegenüberstellung von männlich und schlecht, wo man ein tadelloses männliches Stück auf der einen Seite, ein schlechtes weibliches auf der andern erwarten würde.

Kap. 2. v. 2. Mit ברכֵתכם scheint mir das Nötige getan zu sein. 


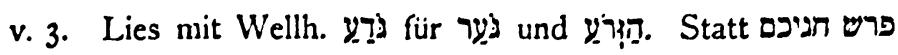

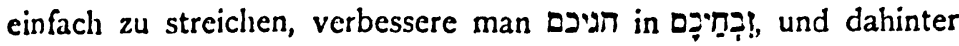
könnte noch הָרְּ ausgefallen oder nach Eintritt der Verderbnis gestrichen sein. Eine Erläutcrung für die derbe Drohung ist keines-

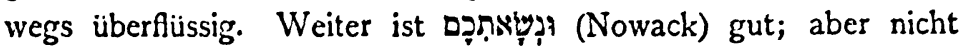
ausreichend dem folgenden gegenüber. Streicht man davon das 1 als Wiederholung des folgenden Buchstaben und wiederholt statt dessen das vorhergehende $D$, so ergibt sich ממל י, was leicht aus aus meiner Gegenwart wäre ein guter Abschlub; etwas Ähnliches jedenfalls ist am Schluß dieser Bedrohung der Priester garnicht

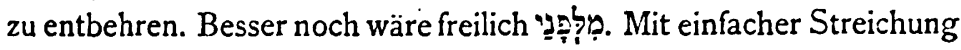
unter Hinweis auf Am 4, 2 (Marti) scheint mir nichts getan zu sein.

v. 4. Für להיות zu denken: weil ein Bund zwischen mir und Levi besteht.

v. 5. Hier wird der Bund nach seinen zwei Seiten auseinandergelegt. Die göttliche reicht bis iואתנם לnrichtig ist es מורא durch vorgesetztes ל dazu zurückzuziehen (Oort), auch bleibt es dann noch kühn zu übersetzen opdat zij mij mochten vreezen. Eher mag man fragen, ob das schließende 1 vor מורא $\mathrm{zu}$ wiederholen ist. Jedenfalls aber bedarf מורא des Suffixes, und zwar

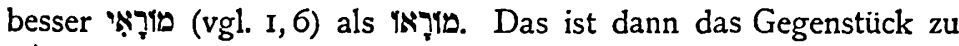
החיים והשלום. Das folgende Verbum wird man imperfektisch sprechen müssen, "י", weil Gottes Anteil zwar Tat und Gabe, des Menschen aber nur Versprechen und Pflicht ist. Also: „Leben und Heil, die gab ich ihm, und meine Furcht, daß er mich fürchten sollte." Danach muß auch ת®: geschrieben werden, wenn man nicht auf נח zurückgehen und unter Wiederholung des , vorher תฺ̣: daß er sich demütige lesen darf. Für imperfektische Haltung spricht auch das היתה in v. 6, das nur bei Änderung der Zeitsphäre einen Ziweck hat.

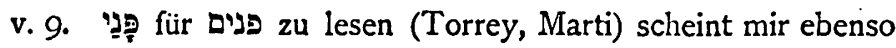
unnötig wie unmöglich.

v. 10. Natürlich ist נבגר, Impf. Kal, zu sprechen.

v. II. Das Verbum בגד wird beibehalten, der Vers schließt 
sich an, als wenn er nur die Ausführung des vorigen wäre. Das ist aber nicht der Fall; denn v. Io rügt die Untreue der Brüder untereinander, v. I I die gegen Jahwe, vgl. ba. Das muß hervorgehoben gewesen sein; für Textverlust spricht auch die Kürze des ersten Gliedes, das nur aus zwei Worten besteht. Er-

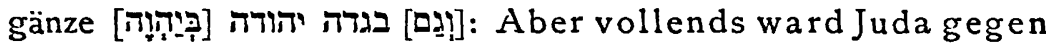
Jahwe treulos, und Sakrileg ist verübt in Jerusalem.

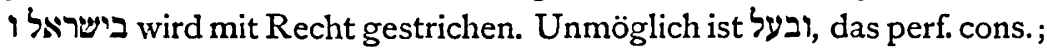
das $I$ ist zurückzuziehen und אִ zu lesen, der ihm Liebe erwiesen, vgl. I, 2. Leicht könnte dahinter ein vạ vor vasgefallen sein.

v. 12. Die Frage, ob ער וענה zu halten ist, will ich nicht von neuem erörtern; jedenfalls muß betont werden, daß alle Gegengründe gegen עלד וענה hinfällig sind. Denn nicht um Zeugen und Ankläger für oder gegen den Übeltäter handelt es sich, sondern um rechtsfähige Nachkommen in kommenden Geschlechtern. Wellhausen's Erklärung ist durchaus richtig. Die Verse I I f. Maleachi abzusprechen (Marti), liegt gar kein Grund vor; im Gegenteil, man beraubt damit den Propheten eines sehr bezeichnenden, seiner Zeit besonders eignenden Zuges.

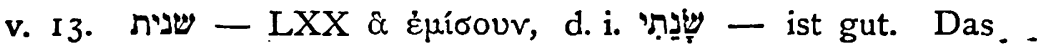
כסות aber muß sofort das Verbrechen bezeichnen; es kann sich daher nicht um das Weinen und Klagen der schuldigen Männer handeln, was ohnehin wunderlich klingt; sondern in der Tat, was man neuerdings allgemein ablehnt, um das der verstoßenen Weiber, das durch die Schuld der Männer vor Jahwe kommt, auch wenn die Weiber das Heiligtam nicht betreten. Alles wird klar, sobald man den falschen Vokalbuchstaben von מאין beseitigt und מאון biest, er [Jahwe] weigert sich. Auch יהוה (Oort) wird dadurch überflüssig.

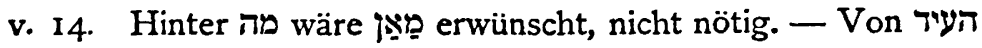
wird das $\pi$ als Wiederholung zu streichen und einfach $7 y$ zu lesen sein; das Verbum kommt in der übrigens so häufigen Wendung nirgends vor.

v. I5. Das erste Glied muß den Sinn haben, daß Einer (טחו) der Schuldige ist, die Andern (שאר) Mitschuldige; jede Her- 
stellung mit anderm Sinne verfehlt das Ziel. In m mub ein Verbum mit der Bedeutung zulassen stecken; ganz leicht gibt sich

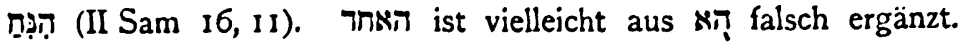
Zu Anfang הליא zu lesen (Wellh. Oort usw.) ist bei richtigem Verständnis keine Verbesserung; natürlich muß ולא als fragend

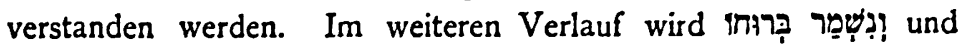
בצוב zu lesen sein: Was aber sucht jener? Gottessame! [d. h. Nachkommenschaft, die doch nur Gott geben kann und nur als gnädiger Gott geben wird]. So wahre er seine Seele und werde dem Weibe seiner Jugend nicht untreu! Man bedenke wohl, daß Hinzunahme eines Weibes zu dem gealterten oder unfruchtbaren hier nicht verboten wird.

v. I6. Die erste Person für שנא ist notwendig, entweder

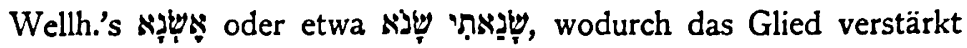
und der Ausfall erklärt würde. Von allen Bekräftigungsformeln in dem Buche könnte das אמר יהוה אלהי ישראל am ersten Zusatz sein, wie Wellh. anzunehmen geneigt ist. Das Zusammenstreichen der Verse, wie Marti es übt, ist unberechtigt.

Kap. 3. v. I. Wie immer man den מלאד דברית deuten möge, die Schwierigkeit des Verses beruht nicht in dessen Einführung an sich, sondern darin, daß in I a der Engel Jahwes als Wegbereiter fur Jahwe selber verheißen wird, in $b \alpha$ der Herr in eigener Person in seinen Tempel einzieht, und in $b \beta$ wieder der Engel des Bundes an seine Stelle tritt, von dessen Kommen und Eingreifen dann zweifellos die Verse 2-4 reden. Nur Stade hat diese Schwierigkeit bemerkt und einen Vorschlag zu ihrer Beseitigung gemacht, vgl. Bibl. Theol. d. A. T. I S. 333 f.

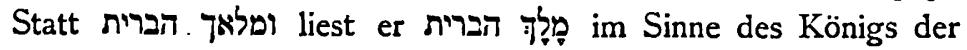
Gemeinde, d. i. natürlich Jahwe. Dann gelten alle Aussagen von I $b$ an nicht (fnem Engel oder Boten sondern Jahwe selbst. Aber die eigentümli, hhe nähere Bestimmung מלך הברית dürfte doch noch schwerer zu erklären sein als מלאך הברית, weil als König nur Einer in Betracht kommen kann. Jedenfalls sind das bloß ver-

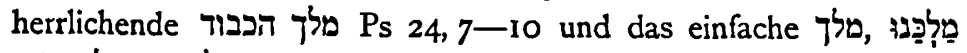
oder מלך ישראל Jes 33, 17. 22. Zeph. 3, 15, die Stade anführt - 
vgl. auch Jes 6,5 - keine ausreichenden Seitenstücke. Dazu kommt, daß Jahwe selbst im letzten Gliede die Ankunft des Ver-

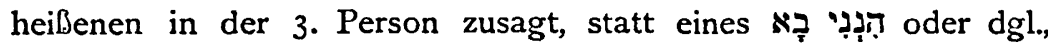
auch in den folgenden Versen doch wohl Jahwe, nicht der Prophet als von ihm unterschieden, von dem Erscheinen und Eingreifen des Verheißenen redet. Das sieht doch sehr bestimmt danach aus, da $\$$ erst von dem Wegbereiten die Rede ist, das in I a dem Engel Jahwes zugewiesen wird. Ich möchte daher vermuten, daß vielmehr in dem אל־היכלו האדון der Fehler steckt. Die leichteste

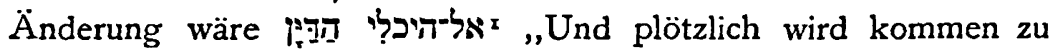
meinem Tempel der Richter (I Sam 24, I6. Ps. 68, 6, auch wohl Hi 19, 29), den ihr verlangt, und der Bundesengel, den ihr begehrt". Dann ist in dem 'הדין וגו deutlich auf die Klage 2, 17, daß man den Gott des Rechtes vermisse, zurückgewiesen, und מלאד הברית gibt die auf I a zurückgreifende nähere Bestimmung. Dieses richtenden.Engels Amt geht dann auf die Reinigung des Heiligtums, insbesondere der Priesterschaft (3a), wodurch das אידיכלי sich daraus vollends auch die richtige Erklärung für den rätselhaften "Engel des Bundes". Denn mit großem Nachdruck ist in 2, 4. 5.8 das besondere Bundesverhältnis hervorgehoben. worden, in dem Jahwe zu den Priestern und nur zu ihnen steht. Dieses Bundesverhältnis wird von den Priestern andauernd verletzt und steht in Gefahr von Jahwe gelöst zu werden. Statt dessen wird er den Engel senden, der über diesem Bunde wacht und ihn durch Heimsuchung und Läuterung der Priesterschaft wieder $z \mathrm{u}$ voller Geltung bringt. Das Ergebnis wird sein, $\mathrm{da}$ Jahwe wieder würdige Priester erhält $(3 \mathrm{~b})$ und darum von neuem wie vor Alters Wohlgefallen an den Opfergaben haben kann (v. 4). Dann erst wird er selber nahen und das Gericht am Volke fortführen (v. 5 f.).

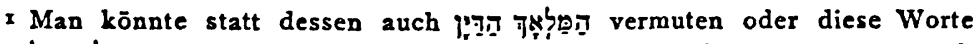
hinter אל-תיכלי die Wiederholung des המלאך wäre ungeschickt. 


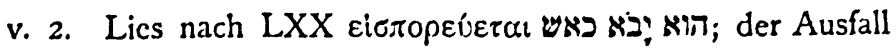
ist leicht erklärlich.

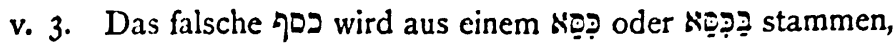
das hinter עישו ליהוה - zu seine Streichen (Marti, wohl wesentlich des Metrums wegen) ist ganz unzulässig; aber dem Metrum wäre auch geholfen durch Änderung in '?, was durch den Zusammenhang geboten erscheint. Es ist irrig zu ליהוה ergänzt worden.

v. 4. Auch hier ist '? ליהוה für herzustellen.

v. 5. Mit Recht streicht Wellh. שכר. Hinter מטי ist wohl מִưg (LXX kpiorv) ausgefallen.

v. $6 f$. Wellhausen sagt zum Schluß von v. 6: „כליתם versteh ich nicht und weiß ich auch nicht zu bessern." Etwas Brauchbares ist auch anderwärts nicht geboten. Der Fehler steckt schwerlich in dem כליתם. Ausgesagt muß sein, daß, wie der Jahwe der Gegenwart noch der der Vorzeit ist, so auch das Israel der Gegenwart nicht anders geworden ist gegenüber den vergangenen sündigen Geschlechtern. Mit diesen muß es also verלמימי אבתיכם glichen, von ihnen daher unterschieden werden. Das dagegen faßt das Israel der Gegenwart mit jenen zusammen. Wahrscheinlich ist also למימ' nicht richtig. Dafür bietet LXX ásò

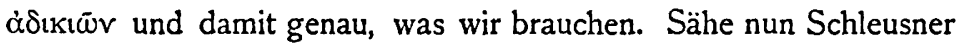

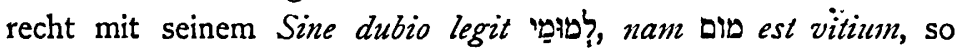
wäre darauf gar nichts zu geben. Aber מום wird bei LXX nirgends

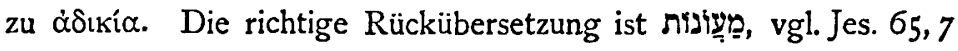
und Lev 16, 22 LXX. Das wird im hebräischen Text übersprungen sein, vielleicht durch einen Hörfehler, und als Lückenbüßer ist dann

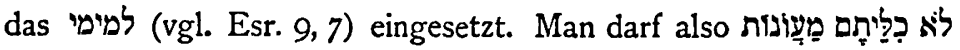
שמרתם (Wellh.) ist nicht eben niftig, weil sich das Objekt von selbst ergänzt. - Ungerechtfertigt $\mathrm{sind}$ auch hier Martis Streichungen.

v. 8. Das erste Glied an den Anfang von v. 9 zu versetzen (Marti), liegt kein andrer Grund vor als der Vierzeiler, der doch nicht wohl mit der Frage bei py schließen konnte. Mit einer rhetorischen Frage beginnt dagegen Jahwes Antwort auch I, 2 b. 
- Auffallend abgerissen klingt die Antwort „Am Zehnten und

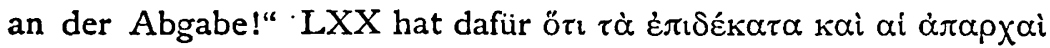

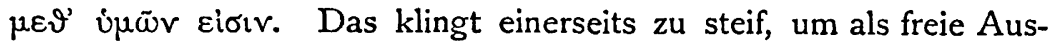
legung der LXX zu gelten, und anderseits wird es sachlich bestätigt durch die Forderung v. Io ,bringt den ganzen Zehnten in

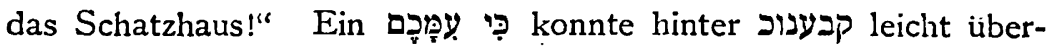
sehen werden. Der so gewonnene Wortlaut „Weil ihr für euch behalten Zehnten und Abgabe!“ klingt doch viel wahrscheinlicher als jene hervorgestoßenen Worte, für die obendrein בַּעשר ובַּרומה $z u$ erwarten wäre.

v. I I f. Wieder sind die Streichungen Martis ganz unberechtigt. Der Gegensatz zwischen Juden und Heiden, gerade in der Verteilung irdischen Segens, ist allerdings bei Maleachi deutlich genug ausgesprochen, und zwar gleich in den ersten Versen I, $2 \mathrm{ff}$. Sehr fein weist Wellhausen zu השליך הש השל Hi. I 5, In auf 33

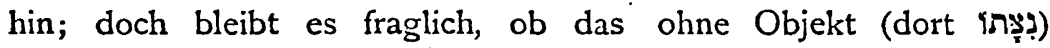
möglich ist.

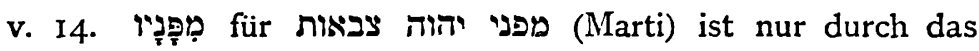
gesuchte Vers- und Strophenmaß bedingt.

v. 16. is ist schon durch das folgende Perfektum verdächtig und gibt auch sonst keinen brauchbaren Sinn. Daß gegenüber . den kleingläubigen Reden v. I4f. hier die Frommen sich untereinander besprächen und stärkten (so wieder Marti), müßte ganz anders und klarer ausgedrückt sein; auch entspricht das נדברו genau dem נדברנו der Frage in v. 13. Daher sind in der Tat die Redner von 16 a die gleichen wie die in v. 13-15: man vergesse doch nicht, daf sie aúsdrücklich unsträflichen Wandel für sich in Anspruch nehmen. Das $\tau \alpha u \tilde{\tau} \propto$ der LXX für is ist somit dem Sinne nach richtig; hebräisches il dafür wird aber von Wellhausen mit Recht nur mit einem Fragezeichen vorgeschlagen. Der richtige

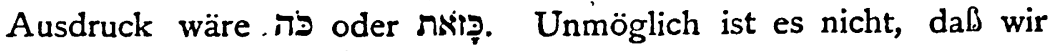
es mit absichtlicher Änderung in der Richtung des u. a. von Marti vertretenen Verständnisses $\mathrm{zu}$ tun haben. Jedenfalls ist auch für

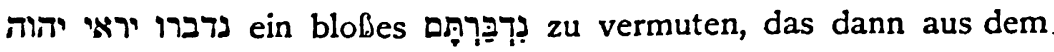
Schlusse des Verses sein explicitum erhalten hat. Beginnt man 
mit ויכתב einen neuen Vers, wie Wellhausen richtig rät, so fehlt die Warnung keineswegs ganz, daß man sich in kleinmütigen Reden

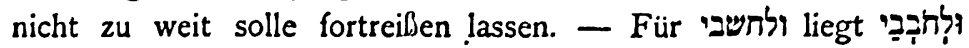

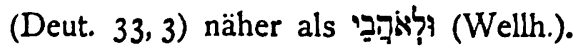

v. 19. Nach LXX mag man עür עש עש lesen. - Sprich nach LXX בiy:- (Wellh. usw.).

v. 21 . כפות wird von LXX nicht übersetzt; es könnte allenfalls aus einer Wiederholung von תrת entwickelt sein. Die Streichungen Martis sind nicht gerechtfertigt.

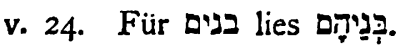

